\title{
IMPLANTATION OF A LEFT VENTRICULAR ASSIST DEVICE, BACK-TO-FRONT, IN AN ADOLESCENT WITH A FAILING MUSTARD PROCEDURE
}

\author{
Lars Wiklund, $\mathrm{MD}, \mathrm{PhD}$, Sveneric Svensson, $\mathrm{MD}, \mathrm{PhD}$, and Håkan Berggren, $\mathrm{MD}, \mathrm{PhD}$, Göteborg, Sweden
}

Implantation of mechanical assist devices has saved the lives of patients awaiting heart transplantation. ${ }^{1}$ The HeartMate left ventricular assist device (Thermo Cardiosystems, Inc, Woburn, Mass) is made to connect the inflow cannula to the apex of the left ventricle. ${ }^{2}$ We describe a successful case in which the device was placed back-to-front with the inflow cannula inserted into the diaphragmatic wall of the right ventricle and the outflow graft through the left side of the diaphragm and in the left pleura to the ascending aorta (Fig 1).

Medical history. A 15-year-old boy who was born with transposition of the great arteries underwent several balloon septostomies at birth because of desaturation. Despite this treatment, the desaturation was persistent. He therefore underwent an operation on an emergency basis at 3 months of age with an atrial switch as described by Mustard (pericardial baffle). At 4 years of age he required a reoperation because of residual atrial shunt and stenosis of the superior vena cava. Ten days after this operation a VVI pacemaker system was implanted because of atrioventricular dissociation. He then had an active life for almost 9 years, after which he gradually noted progressive fatigue and dyspnea. He had a cough, nausea, and cyanosis. Cardiac assessment revealed severe biventricular failure, gross atrioventricular valve regurgitation, and pulmonary hypertension (although reversible), and he was listed for heart transplantation. Despite "optimal" inotropic support, his condition continued to deteriorate with signs of multiorgan failure.

Because no donor was available, we decided to implant a HeartMate left ventricular assist system, even though we expected major technical difficulties since the right ventricle, where the inflow cannula had to be placed, was the systemic ventricle.

Surgical procedure. A median sternotomy was performed, and the heart, which was heavily adherent, was carefully dissected. Because the patient was thin, we decided to place the pump intraperitoneally. ${ }^{3}$ The aorta was cannulated. The systemic atrium was cannulated, and a left-sided bypass was instituted. This made the subsequent cannulation of the cavae

From the Department of Cardiothoracic Surgery, Sahlgrenska University Hospital, S-413 45 Göteborg, Sweden.

Received for publication May 13, 1999; accepted for publication June $14,1999$.

Address for reprints: Lars Wiklund, MD, Department of Cardiothoracic Surgery, Sahlgrenska University Hospital, S-413 45 Göteborg, Sweden.

J Thorac Cardiovasc Surg 1999;118:755-6

Copyright $\odot 1999$ by Mosby, Inc.

$0022-5223 / 99 \$ 8.00+0 \quad \mathbf{1 2 / 5 4 / 1 0 0 7 3 9}$

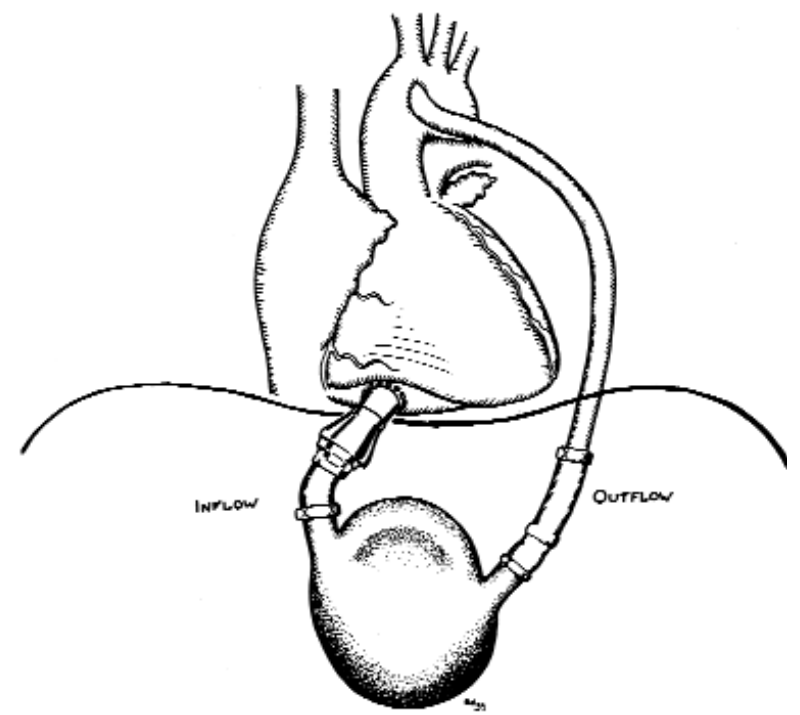

Fig 1. Schematic figure showing the position of the device placed back to-front with the inflow cannula toward the right ventricle and the outflow cannula in the left pleura.

easier. The aorta was crossclamped and blood cardioplegic solution was administered antegradely. The optimal positioning of the HeartMate vented electric device was back-tofront, with the inflow directed toward the diaphragmatic wall of the right ventricle and the outflow toward the apex region. Two incisions were made in the diaphragm corresponding to the inflow and outflow tracts. To avoid damage to the liver, from the front of the pump, we made a "pillow" from polytetrafluoroethylene (Preclude pericardial membrane*) stuffed with Dacron felt. When the device was in place, the inflow was on the right side and the outflow on the left side (Fig 2). An expected pulmonary hypertension was prevented with inhaled aerosolized epoprostenol (prostacyclin). ${ }^{4}$

The early postoperative course in the intensive care unit was uneventful, and after 2 weeks the patient was transferred to the ward. Five weeks after the operation the patient was discharged from the hospital to his home, located $1500 \mathrm{~km}$ from our hospital, to await a donor heart.

Comment. The need for assist devices in patients with complex congenital heart conditions, as after atrial correction for transposition of the great arteries, could be a surgical technical challenge. Because the right ventricle is the systemic ventricle in transposition, several points must be considered. To place the device on the right side in the abdomen

*W. L. Gore \& Associates, Inc, Flagstaff, Ariz. 


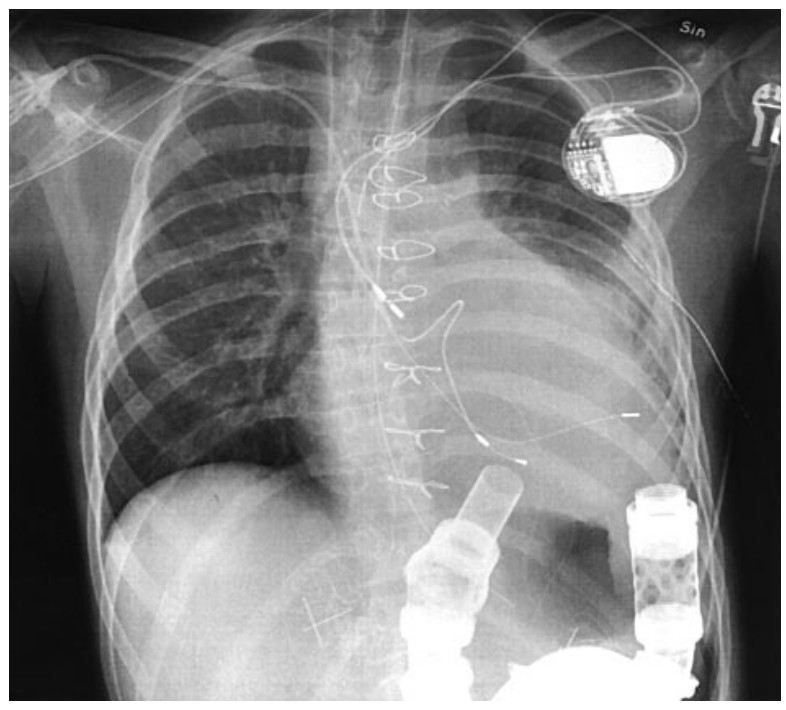

Fig 2. Chest x-ray film showing the device placed in a backto-front position with the inflow graft on the right side and the outflow on the left side.

could be troublesome, as it might compress the liver and create unfavorable angles for the inflow and outflow cannulas, which could result in impaired flows. The trabeculae in the right ventricle could disturb the flow to the inflow cannula, leading to inadequate function of the device. A way to minimize this is to place the cannula on the diaphragmatic wall toward the septum. That worked well in this patient. However, placing the device back-to-front intraperitoneally raised some doubts, although problems did not appear. The device functioned very well. This patient had no major diet problems and no reflux from the stomach. The outflow graft was used in its full length, and as it made its way through the left pleura a major concern was the possibility of kinking. The patient had transient pain from the left hemithorax, probably due to movements of the graft. As yet there have been no signs of major infections.

In conclusion, we were successful in implanting a HeartMate vented electric left ventricular assist system backto-front in a patient with severe heart failure after a failing Mustard procedure.

\section{REFERENCES}

1. Frazier OH, Rose EA, McCarthy P, Burton NA, Tector A, Levin $\mathrm{HR}$, et al. Improved mortality and rehabilitation of transplant candidates treated with a long-term implantable left ventricular assist system. Ann Surg 1995;222:327-38.

2. Poirier VL. The HeartMate blood pump. In: Lewis T, Graham TR, editors. Mechanical circulatory support. London: Edward Arnold; 1995. p. 229-36.

3. Wasler A, Springer WE, Radovancevic B, Myers TJ, Stutts LA, Frazier $\mathrm{OH}$. A comparison between intraperitoneal and extraperitoneal left ventricular assist system placement. ASAIO J 1996;42:M573-6.

4. Haraldsson $\AA$, Kieler-Jensen N, Ricksten S-E. Inhaled prostacyclin for treatment of pulmonary hypertension after cardiac surgery or heart transplantation: a pharmacodynamic study. J Cardiothorac Vasc Anesth 1996;10:854-8. 